Check for updates

Cite this: J. Mater. Chem. A, 2021, 9 , 27448

Received 9th November 2021 Accepted 22nd November 2021 DOI: $10.1039 / \mathrm{d} 1 \mathrm{ta} 09625 \mathrm{~g}$

rsc.li/materials-a

\section{Zeolite-driven Ag species during redox treatments and catalytic implications for $\mathrm{SCO}$ of $\mathrm{NH}_{3} \dagger$}

\author{
Christian W. Lopes, (D) $\ddagger^{a}$ Joaquin Martinez-Ortigosa, (D) a Kinga Góra-Marek, (D) b \\ Karolina Tarach, (ID b José A. Vidal-Moya, (D) a Antonio E. Palomares, (D) a \\ Giovanni Agostini, (iD ${ }^{c}$ Teresa Blasco (ID *a and Fernando Rey (D) ${ }^{a}$
}

Supported silver species are among the most promising catalysts for the depletion of ammonia emission by selective catalytic oxidation ( $\mathrm{NH}_{3}-\mathrm{SCO}$ ). Here, an investigation on the influence of small pore $\mathrm{CHA}$ and $\mathrm{RHO}$ zeolite structures on the silver species formed and their catalytic activity for the $\mathrm{NH}_{3}-\mathrm{SCO}$ reaction has been conducted. To this end, $\mathrm{AgRHO}(4)$ and $\mathrm{AgCHA}(4)$ zeolites with similar Si/Al molar ratios $(\approx 4)$ and silver content $(\sim 15 \mathrm{wt} \%, \mathrm{Ag} / \mathrm{Al} \approx 0.6)$, and $\mathrm{AgCHA}(2)$ with $\mathrm{Si} / \mathrm{Al} \approx 2$ and higher silver loading, while maintaining the $\mathrm{Ag} / \mathrm{Al}$ ratio ( $26 \mathrm{wt} \%, \mathrm{Ag} / \mathrm{Al} \approx 0.6)$, have been submitted to different treatments and characterized by using a large variety of techniques (XRD, UV-Vis, ${ }^{109} \mathrm{Ag} N \mathrm{NR}$, in situ XAS and operando FT-IR). The reduction of the AgCHA and $\mathrm{AgRHO}$ zeolites at low temperature $\left(100-200{ }^{\circ} \mathrm{C}\right)$ produces silver clusters, which remain in the AgRHO zeolite when the temperature is increased to $400{ }^{\circ} \mathrm{C}$. However, the silver species in the AgCHA zeolites evolve to nanoparticles (NPs) at $400{ }^{\circ} \mathrm{C}$ under $\mathrm{H}_{2}$. The catalytic tests show that metal particles are the active sites while silver clusters are inactive for the $\mathrm{NH}_{3}-$ SCO reaction. Also, there are important differences in the stability of the reduced Ag species under oxidizing or under reaction conditions at $400{ }^{\circ} \mathrm{C}$. Metal NPs are partially redispersed and oxidized to $(\mathrm{Ag})_{n}{ }^{+}$, while silver clusters are completely oxidized to $\mathrm{Ag}^{+}$. Our results indicate that silver clusters are stabilized in the $\mathrm{RHO}$-type and not in the $\mathrm{CHA}$-type zeolite, and thus they display very different catalytic activities for the $\mathrm{NH}_{3}$-SCO reaction.

\section{Introduction}

The development of supported sub-nanometric metal moieties, mainly clusters of few atoms and isolated atomic species, has been the focus of many studies as they can be advantageous from different points of view. ${ }^{\mathbf{1}}$ In catalysis, the metal dispersion usually increases the activity which, therefore, is expected to improve on small clusters, even if the electronic properties may vary from conventional particles and cause changes in the catalytic behavior. However, the stabilization of metal atoms or clusters may be difficult because of the strong tendency to form large particles $(d>10 \mathrm{~nm}){ }^{2}$ An approach to prevent the aggregation of sub-nanometer metal species is their encapsulation

\footnotetext{
${ }^{a}$ Instituto de Tecnología Química (Universitat Politècnica de València - Consejo Superior de Investigaciones Cientificas), Avda. de Los Naranjos s/n, Valencia 46022, Spain.E-mail: tblasco@itq.upv.es

${ }^{b}$ Faculty of Chemistry, Jagiellonian University in Kraków, 2 Gronostajowa St., Kraków 30-387, Poland

${ }^{c}$ ALBA Synchrotron Light Source, Crta. BP 1413, Km. 3.3, Cerdanyola del Vallès 08290, Spain

† Electronic supplementary information (ESI) available. See DOI: 10.1039/d1ta09625g

† Universidade Federal do Rio Grande do Sul, Instituto de Química, Laboratório de Reatividade e Catálise, Porto Alegre 91501-970, Brazil.
}

within the pores and cavities of microporous materials, as demonstrated for Pt, Pd, Au, Ag, and metal alloys. ${ }^{3-10}$ The stabilization of metal clusters in zeolite hosts has been used to exploit their unusual structural, physical, electronic, magnetic, optical and biocidal properties, motivating several studies on their growth and stability under different conditions. ${ }^{\mathbf{1 1 - 1 4}}$ The diffusion and coalescence of metal moieties depend on the heating temperature and the gases present, and may occur under reaction conditions provoking catalyst deactivation. The inverse path, i.e., the re-dispersion of large metal particles even to isolated atoms by heating under an oxidizing atmosphere, has also been investigated to regenerate deactivated catalysts. $^{15-17}$

Among supported metals, silver is of particular interest because its semi-noble nature facilitates the reduction of the cation to form sub-nanometer metal entities, including stabilized positively charged species and metal nanoparticles (NPs). The ability of silver to modify its aggregation and oxidation states creates incertitude about the chemical species present during any practical application..$^{\mathbf{1 4 1 8 - 2 1}}$ For this reason, it is very important to identify the species present in supported silver catalysts submitted to different reduction/oxidation treatments during catalyst optimization for specific processes. Besides this, the framework topology can also control the nature of the silver 
species formed in Ag-zeolite stabilizing clusters and atomically dispersed sites, affecting the catalytic performance. However, the influence of the zeolite structure on the state of silver and the catalytic properties has been scarcely investigated.

The selective catalytic oxidation of ammonia $\left(\mathrm{NH}_{3}-\mathrm{SCO}\right)$ to $\mathrm{N}_{2}$ and $\mathrm{H}_{2} \mathrm{O}$ is one of the numerous reactions catalyzed by supported noble metals, with Ag-based catalysts, especially Ag/ $\mathrm{Al}_{2} \mathrm{O}_{3}$, being among the most effective catalysts for said reaction. ${ }^{22-24}$ The $\mathrm{NH}_{3}$-SCO is the most promising method for the depletion of ammonia that is recognized as one of the main emerging atmospheric contaminants with detrimental effects on the environment and human health. ${ }^{25,26}$ Interest in this process has been increasing in recent years, motivated by the ammonia slip to the atmosphere from the selective catalytic reduction of $\mathrm{NO}_{x}\left(\mathrm{NH}_{3}-\mathrm{SCR}-\mathrm{NO}_{x}\right)$ and by the more restricting regulations in gas emissions. The SCR units, fitted in heavy-duty diesel vehicles and power plants for the removal of $\mathrm{NO}_{x}$, use as reducing agent an excess of ammonia, which is generated onboard by urea decomposition. ${ }^{25,27-29}$ During this process, $\mathrm{NH}_{3}$ can be over-oxidized to give other contaminants such as $\mathrm{N}_{2} \mathrm{O}$ and NO. Thus, the catalysts must be optimized to enhance $\mathrm{N}_{2}$ selectivity. In this context, determining the silver species can shed light on the active and selective sites and the reaction pathway, which is assumed to follow the internal SCR (i-SCR) mechanism..$^{19,29,30}$ In general, the activity of Ag-supported catalysts increases with the metal dispersion, while the selectivity to $\mathrm{N}_{2}$ is higher on larger silver particles. ${ }^{31,32}$ A previous study of our group indicates that $\mathrm{Ag}^{+}$sites in $\mathrm{Ag}$-zeolites are practically inactive for the $\mathrm{NH}_{3}$-SCO reaction. ${ }^{33}$ However, there are still controversies about the role played by charged $\left(\mathrm{Ag}_{m}{ }^{\delta+}\right)$ and neutral $\left(\mathrm{Ag}_{n}{ }^{0}\right)$ silver clusters, which are usually also present in supported Ag catalysts.

This work focuses on the characterization of the silver species formed in small-pore Ag-zeolites with the CHA and RHO topologies under different reduction/oxidation conditions to determine the influence of the framework structure and with less detail, of the aluminum content of the zeolite host. The effect of thermal treatments on the silver clustering/aggregation is followed by a suite of in situ and ex situ physicochemical characterization techniques. The results reported here prove that besides the activation treatment and the catalysts' chemical composition, the framework topology plays a key role in the formation of silver species and thus in determining their redox properties and catalytic performance in the $\mathrm{NH}_{3}$-SCO reaction.

\section{Materials and methods}

\subsection{Preparation of Ag-zeolites}

$\operatorname{AgCHA}(2), \operatorname{AgCHA}(4)$ and $\operatorname{AgRHO}(4)$ zeolites were obtained by silver exchange of $\operatorname{KCHA}(2.2), \operatorname{KCHA}(4.2)$ and $\mathrm{NaCsRHO}(4.4)$, respectively, where the values in parentheses indicate the $\mathrm{Si} / \mathrm{Al}$ molar ratio. The parent zeolites were synthesized following the procedure described in the ESI $\dagger$ (zeolite synthesis and preliminary characterization; for XRD and FESEM images, see Fig. S1 and $\mathrm{S} 2 \dagger)$. The $\mathrm{Ag}^{+}$exchange was carried out using an aqueous solution of $\mathrm{AgNO}_{3}$ (ACS reagent 99.9\%) in the appropriate concentration in order to obtain $\mathrm{Ag} / \mathrm{Al}=1 \mathrm{using}$ a solid/ liquid ratio of $1 / 100$ at $25{ }^{\circ} \mathrm{C}$ for $16 \mathrm{~h}$, under mechanical stirring and in darkness to avoid reduction of $\mathrm{Ag}^{+}$to $\mathrm{Ag}^{0}$. Then, the solids were filtered in darkness, washed with distilled water to remove excess silver, dried at $100{ }^{\circ} \mathrm{C}$ for $24 \mathrm{~h}$ and stored in darkness. The chemical composition of the Ag-zeolites is shown in Table 1. The $\mathrm{Na}^{+}$ions present in the parent $\mathrm{NaCsRHO}(4)$ zeolite are selectively replaced by silver, most likely due to its smaller ionic diameter, while $\mathrm{Cs}^{+}$remains in $\operatorname{AgRHO}(4)$. The XRD patterns of the $\operatorname{AgCHA}(2), \operatorname{AgCHA}(4)$ and $\operatorname{AgRHO}(4)$ samples are similar to those of the as-synthesized silver-free zeolites (see Fig. S3†). A AgNaRHO(4) zeolite with a chemical composition similar to that of $\mathrm{AgRHO}(4)$ (see Table 1) was prepared by subsequent $\mathrm{Na}^{+}$exchange until $\mathrm{Cs}^{+}$was fully replaced. Then, $\mathrm{Ag}^{+}$exchange was performed as previously described.

Ag-zeolite samples were thermally reduced under a diluted $\mathrm{H}_{2}$ flow $\left(100 \mathrm{~mL} \min ^{-1}, 10 \% \mathrm{H}_{2} / \mathrm{He}\right)$ at $400{ }^{\circ} \mathrm{C}$ for $40 \mathrm{~min}$ at a heating rate of $10{ }^{\circ} \mathrm{C} \min ^{-1}$ and labeled as $\operatorname{AgCHA}(2)-\mathrm{R}$, $\operatorname{AgCHA}(4)-\mathrm{R}$ and $\mathrm{AgRHO}(4)-\mathrm{R}$. Then, the reduced zeolites were treated in a diluted $\mathrm{O}_{2}$ flow $\left(100 \mathrm{~mL} \min ^{-1}, 10 \% \mathrm{O}_{2} / \mathrm{He}\right)$ at $400{ }^{\circ} \mathrm{C}$ for $40 \mathrm{~min}$ at a heating rate of $10{ }^{\circ} \mathrm{C} \mathrm{min}{ }^{-1}$ and named AgCHA(2)-R-Ox, AgCHA(4)-R-Ox and AgRHO(4)-R-Ox.

\subsection{Characterization techniques}

X-ray diffraction (XRD) patterns were recorded using a Panalytical CubiX3 diffractometer operating at $45 \mathrm{kV}$ and $40 \mathrm{~mA}$ and using $\mathrm{Cu} \mathrm{K} \alpha$ radiation. The experimental XRD patterns of the Ag-zeolites were compared to those of $\mathrm{Ag}^{0}$ (00-004-0783) and $\mathrm{Ag}_{2} \mathrm{O}$ (00-012-0793) JCPDS crystallographic files.

FESEM images were taken using a ZEISS Ultra-55 microscope. The sample powder was deposited using double-carbonsided tape and analyzed without metal covering.

${ }^{109} \mathrm{Ag}$ solid-state NMR spectra were recorded at room temperature with a Bruker AV III HD 400 spectrometer at 18.60 MHz using a $7 \mathrm{~mm}$ probe spinning the samples at $5 \mathrm{kHz}, 14 \mu \mathrm{s}$ as a $90^{\circ}$ pulse and $3 \mathrm{~s}$ as a recycle delay. $\mathrm{Ag}_{3} \mathrm{PO}_{4}$ was used as a secondary reference $\left(\delta{ }^{109} \mathrm{Ag}=342.5 \mathrm{ppm}\right) .{ }^{34}$

A UV-Vis Cary 5000 spectrometer equipped with a diffuse reflectance accessory (Praying Mantis Harrick) was used for recording UV-Vis spectra and $\mathrm{BaSO}_{4}$ was used as a standard for background measurement. The spectra of Ag-zeolites after reduction were immediately measured after $\mathrm{H}_{2}$ treatment to avoid silver oxidation.

FT-IR experiments were performed using a Vertex 70 spectrometer (Bruker). Before FT-IR studies, the zeolite samples

Table 1 Chemical composition of Ag-loaded zeolites

\begin{tabular}{|c|c|c|c|c|c|}
\hline Sample & $\mathrm{Si} / \mathrm{Al}_{\mathrm{EDX}}$ & $\mathrm{Si} / \mathrm{Al}_{\mathrm{NMR}}$ & $\mathrm{Ag} / \mathrm{Al}_{\text {EDX }}$ & $\left(\mathrm{Ag}^{+}+\mathrm{M}^{+}\right) / \mathrm{Al}_{\mathrm{EDX}}$ & $\mathrm{Ag}$ wt $\%$ \\
\hline $\operatorname{AgCHA}(2)$ & 2.2 & 2.2 & 0.7 & $1.0\left(\mathrm{~K}^{+}\right)^{a} \mathrm{a}$ & 26 \\
\hline $\operatorname{AgCHA}(4)$ & 4.2 & 4.1 & 0.5 & $0.9\left(\mathrm{~K}^{+}\right)^{a} \mathrm{a}$ & 14 \\
\hline AgRHO(4) & 4.4 & 4.5 & 0.7 & $1.1\left(\mathrm{Cs}^{+}\right)^{a} \mathrm{a}$ & 16 \\
\hline AgNaRHO(4) & 4.3 & - & 0.6 & $0.9\left(\mathrm{Na}^{+}\right)^{a} \mathrm{a}$ & 16 \\
\hline
\end{tabular}

${ }^{a}$ Co-cation $\left(\mathrm{M}^{+}=\mathrm{Cs}^{+}, \mathrm{K}^{+}, \mathrm{Na}^{+}\right)$present after the silver ion-exchange procedure. Similar $\mathrm{Si} / \mathrm{Al}$ ratios were obtained by EDX and ${ }^{29} \mathrm{Si}$ NMR, excluding extra framework $\mathrm{Al}$, as confirmed by ${ }^{27} \mathrm{Al} \mathrm{NMR}$ spectroscopy. 
were pressed into self-supporting wafers ( $\left.\mathrm{ca} .5 \mathrm{mg} \mathrm{cm}^{-2}\right)$ and thermally treated in an in situ IR cell at $400{ }^{\circ} \mathrm{C}$ at a heating rate of $10{ }^{\circ} \mathrm{C} \mathrm{min}^{-1}$ under vacuum for $30 \mathrm{~min}$. Then, the samples were cooled down to $200{ }^{\circ} \mathrm{C}$, and reduced with deuterium (106 mbar, MATHESON) at this temperature up to 300 s. Subsequently, the samples were evacuated at $200{ }^{\circ} \mathrm{C}$ for $20 \mathrm{~min}$ and oxidized with $\mathrm{O}_{2}$ (106 mbar, MESSER, 5.0) at the same temperature up to $300 \mathrm{~s}$. Rapid scan FT-IR spectra were recorded every $0.6 \mathrm{~s}$ under operando conditions during the reduction and subsequent oxidation at $200{ }^{\circ} \mathrm{C}$. This temperature was chosen as most suitable for following the reversibility of the reduction-oxidation process to ensure the removal of formed water. Afterward, the samples were heated up to $400{ }^{\circ} \mathrm{C}$ at $10{ }^{\circ} \mathrm{C} \mathrm{min}{ }^{-1}$ and kept for $20 \mathrm{~min}$ in contact with $\mathrm{O}_{2}$. After the oxidation process, the samples were cooled down to room temperature and in situ CO sorption (PRAXAIR, 4.8) was performed. Based on earlier studies, ${ }^{19,35}$ quantitative analysis of the $\mathrm{Ag}$ species present in the samples was carried out.

X-ray absorption experiments at the Ag K-edge (25 $514 \mathrm{eV}$ ) were performed at the BL22 (CLÆSS) beamline of the ALBA synchrotron (Cerdanyola del Vallès, Spain). ${ }^{36}$ The white beam was monochromatized using a Si (311) double crystal cooled by liquid nitrogen; harmonic rejection has been performed using Rhcoated silicon mirrors. The spectra were collected in transmission mode by means of ionization chambers filled with appropriate gases $\left(88 \% \mathrm{~N}_{2}+12 \% \mathrm{Kr}\right.$ for $\mathrm{I}_{0}$ and $100 \% \mathrm{Kr}$ for $\left.\mathrm{I}_{1}\right)$. Samples in the form of self-supported pellets of optimized thickness have been located inside an in situ cell described by Guilera el al. ${ }^{37}$ XAS spectra of the samples were collected upon reduction at $100{ }^{\circ} \mathrm{C}, 200{ }^{\circ} \mathrm{C}$ and $400{ }^{\circ} \mathrm{C}$ following the temperature profiles shown in Fig. S4. $\dagger$ All the samples were subsequently oxidized at $400{ }^{\circ} \mathrm{C}$ following the profile shown in Fig. S4a. $\dagger$ Several scans were acquired at each measurement step (allowing $20 \mathrm{~min}$ for temperature stabilization in each step) to ensure spectral reproducibility and a good signal-to-noise ratio. The data reduction and extraction of the $\chi(k)$ function have been performed using the Athena code. ${ }^{38}$ EXAFS data analysis has been performed using Artemis software. ${ }^{38}$ The methodology of data fitting consists of a co-refinement approach in which determined parameters are constrained to decrease correlation problems usually found in XAS data analysis. As a common strategy, $\Delta E_{0}$ is allowed to vary but is fixed (and equal) for spectra with atoms in the same local environment and the Debye-Waller factor (DWF) can be constrained considering similar disorder within the absorber atoms. This strategy was adopted due to the reliability of the fits in terms of small errors. Additional information will be displayed as a note below the table of EXAFS results. Phases and amplitudes have been calculated with the FEFF6 code using crystallographic files for well-known Ag-based standards as input. In the case of the asobtained $\operatorname{AgCHA}(2)$ and $\operatorname{AgRHO}(4)$ spectra, crystallographic data of similar materials were used, which were modified to obtain experimentally reasonable results.

\section{$2.3 \quad \mathrm{NH}_{3}$-SCO catalytic experiments}

$\mathrm{NH}_{3}$-SCO-activity measurements over the Ag-zeolite catalysts were carried out in a fixed-bed quartz tubular reactor of $1.2 \mathrm{~cm}$ diameter and $20 \mathrm{~cm}$ length, using a gas mixture of $500 \mathrm{ppm}$ $\mathrm{NH}_{3}, 7$ vol\% $\mathrm{O}_{2}$ and $\mathrm{N}_{2}$ as a balance. The total flow rate and amount of catalyst were $0.8 \mathrm{~L} \mathrm{~min}^{-1}$ and $0.25 \mathrm{~g}$, respectively, resulting in a $192 \mathrm{~L} \mathrm{~h}^{-1} \mathrm{~g}^{-1}$ WHSV for the catalytic experiments. Three online detectors were used to analyze the outlet gases: a UV-based detector for monitoring $\mathrm{NH}_{3}$ (Tethys Instruments EMX400), an infrared analyzer for $\mathrm{N}_{2} \mathrm{O}$ analysis (Servomex 4900) and a chemiluminescence analyzer which allows the quantification of $\mathrm{NO}_{x}$ concentration (Thermo 42C).

\section{Results and discussion}

The silver-exchanged zeolites with the chemical compositions summarized in Table 1 were characterized by the combination of several spectroscopic techniques. All samples have similar $\mathrm{Ag} / \mathrm{Al}$ molar ratios $\approx 1$, suggesting that all Ag-zeolites underwent nearly full $\mathrm{Ag}^{+}$exchange. Thus, $\mathrm{AgCHA}(2)$ with a lower $\mathrm{Si} / \mathrm{Al}$ ratio $(\mathrm{Si} / \mathrm{Al} \approx 2)$ has higher silver content $(\sim 26 \mathrm{wt} \%)$ than the two other $\mathrm{AgCHA}(4)$ and $\mathrm{AgRHO}(4)$ zeolites $(\mathrm{Si} / \mathrm{Al} \approx 4 ; \sim 15 \mathrm{wt} \%$ $\mathrm{Ag})$. The presence of compensating $\mathrm{Ag}^{+}$cations was confirmed by EXAFS data (Fig. S5, S6 and Table S1 $\dagger$ ), which show that $\mathrm{Ag}^{+}$ is coordinated to two $\mathrm{O}$ atoms at Ag-O distances of $2.26 \AA$ and $2.43 \AA$, respectively, with an average coordination number close to three, in good agreement with previous results reported for the AgLTA zeolite. ${ }^{39}$ The presence of silver as $\mathrm{Ag}^{+}$in the Agzeolites is further supported by a signal at $\delta{ }^{109} \mathrm{Ag}$ around $40 \mathrm{ppm}$ in the solid-state NMR spectra and a band at $220 \mathrm{~nm}$ in the UV-Vis spectra (see Fig. S7†).

\subsection{The state of silver in Ag-zeolites upon reduction under hydrogen}

The reduction of $\mathrm{Ag}^{+}$was studied by treating the $\mathrm{Ag}$-exchanged zeolites under hydrogen at $400{ }^{\circ} \mathrm{C}$. The X-ray diffractograms, displayed in Fig. 1, show the characteristic patterns of the CHA(Fig. 1a) or RHO- (Fig. 1b) type zeolite accompanied by the characteristic diffraction lines of silver metal, with a relative intensity that depends on the sample. So, the diffraction peaks of the $\mathrm{Ag}^{0}$ metal are considerably less intense for the $\mathrm{AgRHO}(4)$ $\mathrm{R}$ when compared with the $\operatorname{AgCHA}(4)-\mathrm{R}$ with similar silver loading, indicating that at least in sample $\mathrm{AgRHO}(4)-\mathrm{R}$, there must be smaller NPs or other species such as metal clusters, not observable by XRD. To gain additional information on the species formed, the reduced Ag-zeolite samples were characterized by XAS and UV-Vis spectroscopies.

Fig. 2 shows the $|\mathrm{FT}|$ spectra of the $\operatorname{AgCHA}(2)-\mathrm{R}, \operatorname{AgCHA}(4)-\mathrm{R}$ and $\mathrm{AgRHO}(4)-\mathrm{R}$ zeolites and of silver foil used as a reference, all of them containing only a peak centered at about $2.6 \AA$ due to the $\mathrm{Ag}-\mathrm{Ag}$ bond. The intensity of the $\mathrm{Ag}-\mathrm{Ag}$ peak for the two AgCHA zeolites is similar to that of metal foil, while that of $\mathrm{AgRHO}(4)-\mathrm{R}$ is considerably weaker. Indeed, the analysis of the EXAFS oscillations (curve-fittings shown in Fig. S8†) leads to the structural data summarized in Table 2. The Ag-Ag coordination number is similar to that of the metal foil $\left(\mathrm{CN}_{\mathrm{Ag}-\mathrm{Ag}} \approx 12\right)$ for the two chabazite samples (AgCHA(2)-R and $\operatorname{AgCHA}(4)-\mathrm{R})$ and significantly smaller $\left(\mathrm{CN}_{\mathrm{Ag}-\mathrm{Ag}} \approx 8.6\right)$ for the $\mathrm{AgRHO}(4)$-R zeolite. Therefore, besides silver NPs, the $\operatorname{AgRHO}(4)-\mathrm{R}$ zeolite must 

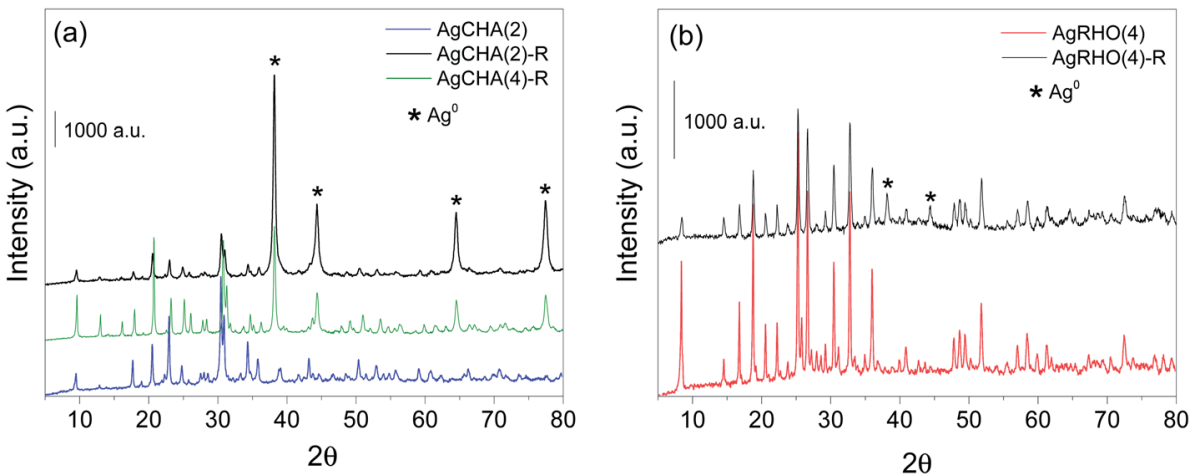

Fig. 1 X-ray diffractograms of $\mathrm{AgCHA}$ (a) and $\mathrm{AgRHO}$ (b) zeolites in their as-obtained and reduced states.

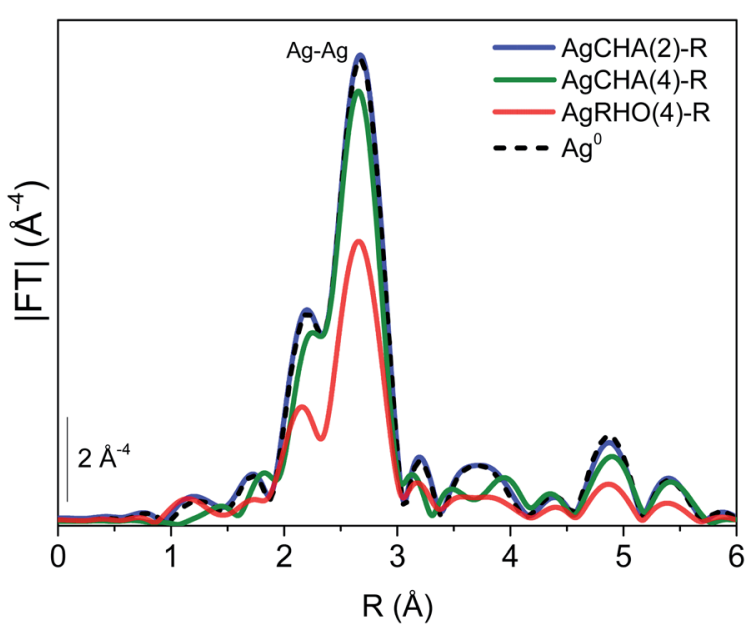

Fig. $2|\mathrm{FT}|$ of the $k^{3}$-weighted EXAFS spectra of the $\operatorname{AgCHA}(2)$, $\mathrm{AgCHA}(4)$ and $\mathrm{AgRHO}$ (4) zeolites treated under hydrogen at $400{ }^{\circ} \mathrm{C}$. The reduced samples were cooled down to $\mathrm{RT}$ under a $\mathrm{H}_{2}$ atmosphere before data collection to minimize the DWF and allow direct comparison.

contain small aggregates of silver atoms, thus decreasing the average $\mathrm{Ag}-\mathrm{Ag}$ coordination number.

The complete reduction of isolated $\mathrm{Ag}^{+}$cations is supported by the absence of any signal in the high field spectral region of the ${ }^{109} \mathrm{Ag}$ NMR $\left(\delta{ }^{109} \mathrm{Ag} \approx 40 \mathrm{ppm}\right)$ representative of $\mathrm{Ag}^{+}$ (Fig. S9†). Indeed, the spectra of the reduced Ag-zeolites consist of a unique resonance at $\delta^{109} \mathrm{Ag} \approx 5270 \mathrm{ppm}$ assigned to $\mathrm{Ag}^{0}$ as illustrated in Fig. 3 for the $\operatorname{AgCHA}(2)-\mathrm{R}$ and $\operatorname{AgRHO}(4)-\mathrm{R}$

Table 2 Summary of the EXAFS fit of the reduced $\mathrm{Ag}$-loaded zeolites $^{a}$

\begin{tabular}{llllll}
\hline Sample & CN & $R(\AA)$ & $\sigma^{2}\left(\AA^{2}\right)$ & $\Delta E_{0}(\mathrm{eV})$ & $r$-factor \\
\hline AgCHA(2)-R & $11.1(8)$ & $2.852(12)$ & $0.0093(6)$ & $2.0(5)$ & 0.0045 \\
AgCHA(4)-R & $11.3(6)$ & $2.857(2)$ & $0.0102(5)$ & & 0.0029 \\
AgRHO(4)-R & $8.6(7)$ & $2.850(14)$ & $0.0114(9)$ & & 0.0085 \\
AgNaRHO-R & $9.3(5)$ & $2.845(3)$ & $0.0124(6)$ & & 0.0032
\end{tabular}

${ }^{a}$ The fits were performed on the first coordination shell $(\Delta R=2.0-3.0$ $\AA)$ over FT of the $k^{1} k^{2} k^{3}$-weighted $\chi(k)$ functions performed in the $\Delta k$ $=2.3-11.8 \AA^{-1}$ interval. $S_{0}{ }^{2}=0.80$. zeolites. The shape of the peak of $\operatorname{AgCHA}(2)-\mathrm{R}$ is quite similar to that of silver metal used as a reference, while that of $\mathrm{AgRHO}(4)-\mathrm{R}$ is significantly narrower in agreement with the lower aggregation of silver in this sample.

The differences in the aggregation state of silver in the AgCHA and AgRHO samples are evidenced by the UV-Vis spectra shown in Fig. 4. The two AgCHA zeolites yield similar spectra displaying two broad bands with one maximum at 375-400 nm assigned to silver NPs and another one at $\sim 275 \mathrm{~nm}$ that may contain signals from $\mathrm{Ag}_{m}{ }^{\delta+}$ and/or $\mathrm{Ag}_{n}{ }^{0}$ clusters. ${ }^{40}$ Meanwhile, the spectrum of the $\operatorname{AgRHO}(4)-\mathrm{R}$ zeolite (see Fig. 4) is quite different, presenting distinct absorption bands in the region between $250 \mathrm{~nm}$ and $400 \mathrm{~nm}$. Although the interpretation of the UV-Vis spectra and the assignment of the UV-Vis bands to specific silver species are uncertain, according to literature data, the bands at $310 \mathrm{~nm}$ and $325 \mathrm{~nm}$ can be tentatively assigned to $\mathrm{Ag}_{8}$ and the band at $\approx 360 \mathrm{~nm}$ to larger $\mathrm{Ag}_{n}{ }^{0}$ clusters. It must be noted that the spectrum of the $\operatorname{AgRHO}(4)-\mathrm{R}$ zeolite also shows a weak component at 400-450 $\mathrm{nm}$ indicating the presence of some metal NPs. ${ }^{40}$ Fig. S10 $†$ shows the TEM images of the $\mathrm{AgCHA}(2)-\mathrm{R}$ and $\mathrm{AgRHO}(4)-\mathrm{R}$ zeolites (reduced under $\mathrm{H}_{2}$ at 400 $\left.{ }^{\circ} \mathrm{C}\right)$. In this figure, it is evident that $\operatorname{AgRHO}(4)-\mathrm{R}$ zeolite has

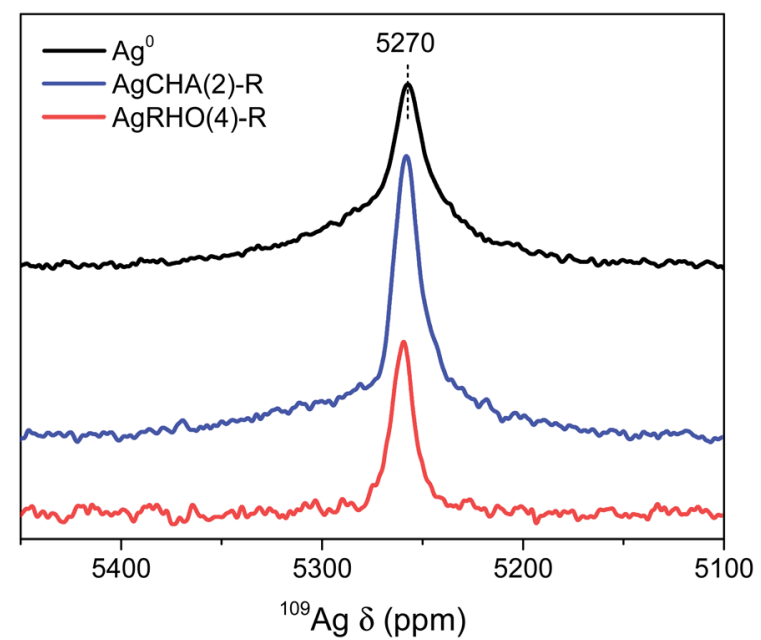

Fig. $3{ }^{109} \mathrm{Ag}$ MAS NMR spectra of $\mathrm{Ag}$ metal and $\mathrm{AgCHA}(2)$ and $\mathrm{AgRHO}(4)$ zeolites treated under hydrogen at $400{ }^{\circ} \mathrm{C}$. 


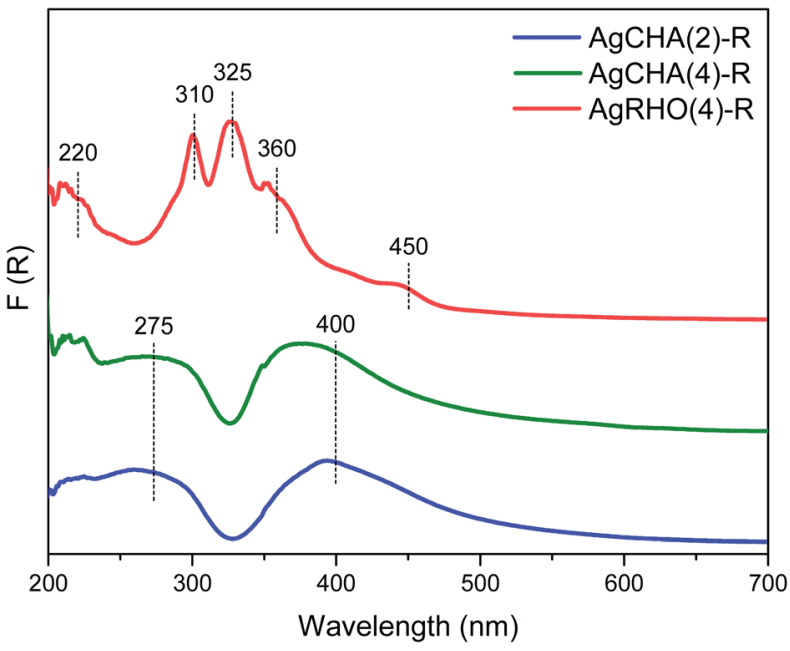

Fig. 4 UV-Vis spectra of $\mathrm{AgCHA}(2), \mathrm{AgCHA}_{(4)}$ and $\mathrm{AgRHO}(4)$ treated under $\mathrm{H}_{2}$ at $400^{\circ} \mathrm{C}$.

a much lower concentration of metal nanoparticles at its external surface. This indirectly indicates that most of the Ag remains inside the zeolite cavities as clusters.

Therefore, the results reported here indicate that although some metal NPs must be present, silver clusters are dominant in the AgRHO(4)-R zeolite, while most silver atoms are involved in metal NPs in the two Ag-chabazites. Besides the zeolite topology, the main difference between the two types of material is the alkaline co-cation compensating for the framework charge, $\mathrm{K}^{+}$for the two AgCHA zeolites and $\mathrm{Cs}^{+}$for the AgRHO zeolite. The $\mathrm{Cs}^{+}$acting as a compensating co-cation in the $\operatorname{AgRHO}(4)$ zeolite is bulkier than the $\mathrm{K}^{+}$and might hinder the diffusion of silver atoms within the zeolite, inhibiting the formation of metal NPs at relatively high temperatures. To check this hypothesis, the AgNaRHO zeolite with a chemical composition similar to AgRHO(4) but containing $\mathrm{Na}^{+}$instead of $\mathrm{Cs}^{+}$(see Table 1) was prepared and the corresponding reduced sample (at $400{ }^{\circ} \mathrm{C}$ ) was analyzed by XAS and UV-Vis spectroscopies (Fig. S11 and S12). $\dagger$ The curve-fitting of the EXAFS oscillations of the AgNaRHO zeolite (Fig. S11 $\dagger$ ) gives a Ag-Ag coordination number of $\sim 9.3$ and $R_{\mathrm{Ag}-\mathrm{Ag}} \approx 2.84 \AA$, close to those obtained for $\operatorname{AgRHO}(4)-\mathrm{R}$ (see Table 2), indicating that the average $\mathrm{Ag}-\mathrm{Ag}$ coordination is similar for the two AgRHO zeolites containing $\mathrm{Cs}^{+}$or $\mathrm{Na}^{+}$as a co-cation. Also, the UV-Vis spectra of AgNaRHO(4)-R and AgRHO(4)-R (see Fig. S12†) are consistent with the predominance of silver clusters in the two samples. These results confirm that the preferred formation of small aggregates of few silver atoms in the AgRHO zeolite and of $\mathrm{Ag}^{0}$ NPs in the AgCHA zeolites is determined by the framework topology and not by the alkaline co-cation.

Since Ag NPs are the predominant Ag species in AgCHA zeolites upon reduction at $400{ }^{\circ} \mathrm{C}$, the study of $\mathrm{Ag}$ aggregation under reduction conditions was performed at lower temperatures. The analysis of the EXAFS data and the UV-Vis spectra of the $\operatorname{AgCHA}(2)$ reduced at $100{ }^{\circ} \mathrm{C}$ and $200{ }^{\circ} \mathrm{C}$ are provided in the ESI (Fig. S13-S15†). The $|\mathrm{FT}|$ of the EXAFS data shows the growth of the $\mathrm{Ag}-\mathrm{Ag}$ peak as the temperature rises from $100{ }^{\circ} \mathrm{C}$ to $200^{\circ} \mathrm{C}$, but with the intensity lower than that of the silver foil. Indeed the $\mathrm{Ag}-\mathrm{Ag}$ coordination number of $\mathrm{AgCHA}(2)$ is around $\mathrm{N}_{\mathrm{Ag}-\mathrm{Ag}} \approx 7$ at $200^{\circ} \mathrm{C}$ (Table S2 $\uparrow$ ). Accordingly, the UV-Vis spectra (Fig. S15†) show discrete absorption bands between $250 \mathrm{~nm}$ and $400 \mathrm{~nm}$, indicating that silver clusters are the main species in the $\operatorname{AgCHA}(2)$ zeolite reduced at $100-200{ }^{\circ} \mathrm{C}$. Therefore, it is possible to stabilize silver clusters of few atoms in the AgCHA zeolite by decreasing the reduction temperature. Comparing this behavior to that observed for the $\mathrm{AgRHO}(4)$ zeolite, it can be concluded that similar Ag species are formed in both materials but at different temperatures, suggesting that the reducibility of $\mathrm{Ag}$ species differs depending on the zeolite structure.

Thus, the influence of the framework topology on the reducibility of atomic $\mathrm{Ag}^{+}$at $200{ }^{\circ} \mathrm{C}$ to form silver clusters was investigated by means of rapid scan FT-IR spectroscopy (one spectrum taken every $0.6 \mathrm{~s}$ ) under operando conditions using $\mathrm{D}_{2}$. To keep the charge neutrality of the Ag-zeolites, the reduction of $\mathrm{Ag}^{+}$to $\mathrm{Ag}^{0}$ is accompanied by the formation of $\mathrm{Si}(\mathrm{OD}) \mathrm{Al}$ groups, which gives high frequency (HF) $\mathrm{Si}(\mathrm{OD}) \mathrm{Al}_{\mathrm{HF}}$ and low frequency
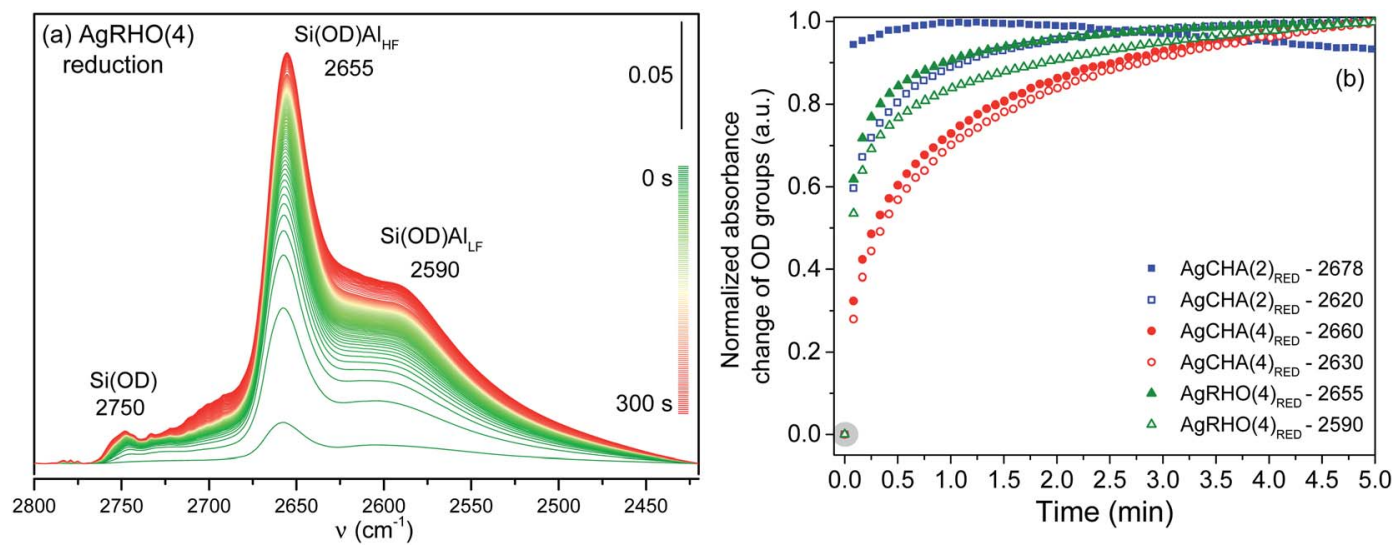

Fig. 5 (a) Time-resolved rapid scan FT-IR spectra in the region of O-D stretching vibrations of $\mathrm{AgRHO}(4)$ in contact with $\mathrm{D}_{2}$ at $200{ }^{\circ} \mathrm{C}$ for 5 min. (b) Normalized trace of the absorbance change of high- and low-frequency OD group bands during reduction with $D_{2}$ at $200{ }^{\circ} \mathrm{C}$ for 5 min. Note: the grey circle represents the starting point (in time) of all normalized bands. 


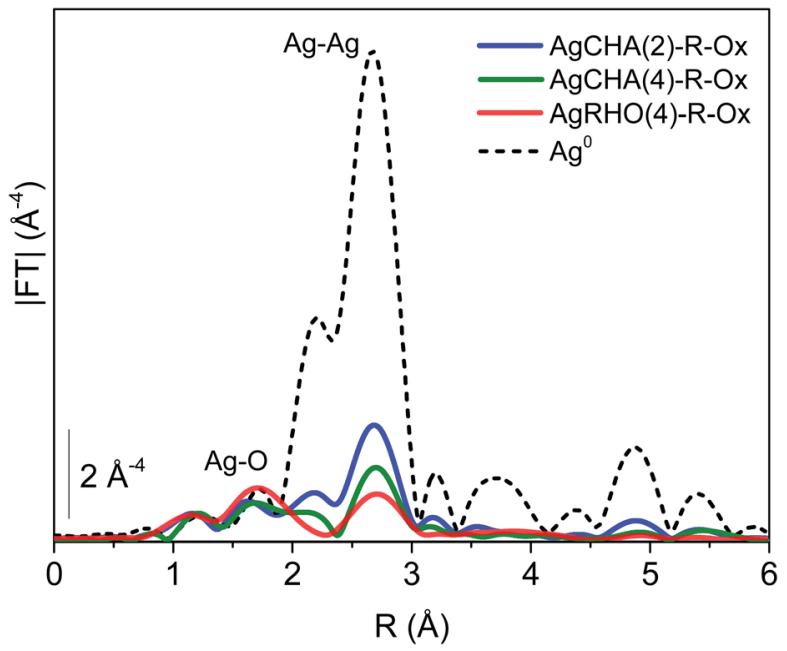

Fig. $6|\mathrm{FT}|$ of the $k^{3}$-weighted EXAFS spectra of the $\operatorname{AgCHA}(2)$, $\mathrm{AgCHA}(4)$ and $\mathrm{AgRHO}(4)$ samples reduced at $400^{\circ} \mathrm{C}$ and subsequently treated under $\mathrm{O}_{2}$ at $400{ }^{\circ} \mathrm{C}$.

(LF) $\mathrm{Si}(\mathrm{OD}) \mathrm{Al}_{\mathrm{LF}}$ bands in the $2800-2450 \mathrm{~cm}^{-1}$ region associated with different oxygen sites of the zeolite framework. The development of OD bands as a function of the heating time is illustrated in Fig. 5a for zeolite $\mathrm{AgRHO}(4)$ (Fig. S16† for zeolites $\operatorname{AgCHA}(2)$ and $\operatorname{AgCHA}(4))$ while Fig. 5b compares the evolution of the normalized intensity of the HF and LF bands for the three $\mathrm{Ag}$-zeolites. For the CHA type structure, the HF band is associated with -OD groups exposed to the barrel-shaped cages (rth cavity), which are interconnected by eight-membered ring windows. ${ }^{41}$ The data plotted in Fig. $5 \mathrm{~b}$ indicate that the HF band appears immediately after adding $\mathrm{D}_{2}$ for the $\operatorname{AgCHA}(2)$ sample and reaches the maximum intensity after heating for $50 \mathrm{~s}$, whereas it requires at least $150 \mathrm{~s}$ for $\operatorname{AgCHA}(4)$, indicating that the aggregation of $\mathrm{Ag}_{n}{ }^{0}$ in the CHA cavities is favoured at higher silver loading. Regarding the kinetics of Ag reduction, the intensity of the $\mathrm{Si}(\mathrm{OD}) \mathrm{Al}$ bands increases more rapidly for the $\operatorname{AgRHO}(4)$ than for the $\operatorname{AgCHA}(4)$ zeolite. Thus, when the two zeolite types having similar Si/Al molar ratio are considered, the reduction is more favorable for AgRHO than for AgCHA zeolites.

\subsection{The state of silver after oxidation of reduced Ag-zeolites}

As mentioned in the introduction, heating under an oxidizing atmosphere increases the dispersion of noble metal particles and may be a potential alternative for obtaining silver clusters or even atomically dispersed species in small pore zeolites. For this purpose, the AgCHA and AgRHO zeolites reduced at $400{ }^{\circ} \mathrm{C}$, containing mainly NPs and clusters, respectively, were treated under oxygen at $400{ }^{\circ} \mathrm{C}$ and fully characterized to identify the formed silver species.

The XRD patterns of the Ag-zeolites show that oxidation of the reduced zeolites provokes a sharp decrease in the intensity of the peaks of metallic Ag in the AgCHA zeolites and their disappearance in the AgRHO (see Fig. S17†). These changes indicate that, effectively, the oxidation treatment provokes the
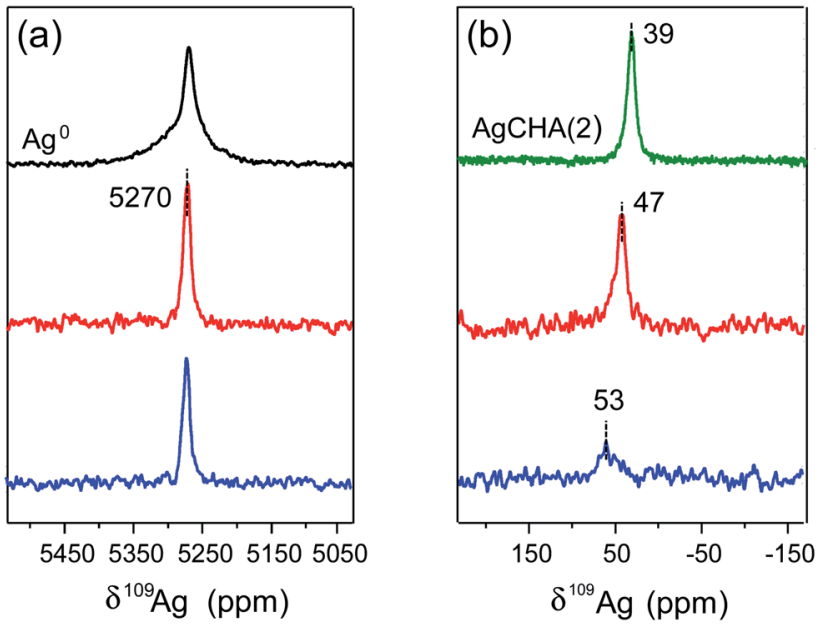

Fig. $7{ }^{109} \mathrm{Ag}$ MAS NMR spectra in the regions of $\mathrm{Ag}^{0}(\mathrm{a})$ and $\mathrm{Ag}^{+}$(b) of the AgCHA(2)-R-Ox (blue) and AgRHO(4)-R-Ox (red) zeolites. Ag metal (black) and $\mathrm{AgCHA}(2)$ (green) are the references for $\mathrm{Ag}^{0}$ and $\mathrm{Ag}^{+}$, respectively.

dispersion of the silver NPs in the two zeolites. More information is gained by the study of the oxidation process by means of XAS and UV-Vis spectroscopies.

Fig. 6 shows the $|\mathrm{FT}|$ of the $k^{3}$-weighted EXAFS spectra of the $\mathrm{Ag}$-zeolites reduced and oxidized at $400{ }^{\circ} \mathrm{C}(\operatorname{AgCHA}(2)-\mathrm{R}-\mathrm{Ox}$, $\operatorname{AgCHA}(4)-\mathrm{R}-\mathrm{Ox}$, and $\mathrm{AgRHO}(2)-\mathrm{R}-\mathrm{Ox})$. Comparison of the spectra of the reduced samples (see Fig. 2) with those of the oxidized materials (Fig. 6) shows a sharp decrease of the $\mathrm{Ag}-\mathrm{Ag}$ contribution indicating the dispersion of the metal NPs. Moreover, the spectra show a peak of $\mathrm{Ag}-\mathrm{O}$ similar to that observed in the as-prepared samples suggesting that some silver is oxidized to $\mathrm{Ag}^{+}$, besides the metal dispersion. The shapes of the FT spectra of the two AgCHA samples are similar, while that of the AgRHO(2)-R-Ox zeolite is slightly different, with a smaller $\mathrm{Ag}-\mathrm{Ag}$ contribution and larger $\mathrm{Ag}-\mathrm{O}$ signal than those observed in CHA zeolites. Quantitative estimation of the $\mathrm{Ag}-\mathrm{Ag}$ coordination number and interatomic distances is challenging due to overlapping between the contributions from the scattering of silver nanoparticles and the higher shells of cationic silver. Nevertheless, the main features of the FT spectra of the oxidized $\mathrm{Ag}$-zeolites indicate that $\mathrm{Ag}^{0}$ NPs are dispersed and oxidized to $\mathrm{Ag}^{+}$upon treatment under $\mathrm{O}_{2}$ to a higher extent for the AgRHO zeolite.

Further information on the oxidation state of the dispersed species on the oxidized samples was obtained by solid-state NMR and UV-Vis spectroscopies. The ${ }^{109} \mathrm{Ag}$ NMR spectra of the $\operatorname{AgCHA}(2)-\mathrm{R}-\mathrm{Ox}$ and $\mathrm{AgRHO}(4)-\mathrm{R}-\mathrm{Ox}$ zeolites, shown in Fig. 7, contain two peaks at $\delta{ }^{109} \mathrm{Ag} \approx 5270 \mathrm{ppm}$ (Fig. 7a) and $\delta{ }^{109} \mathrm{Ag} \approx 40-50 \mathrm{ppm}$ (Fig. 7b) assigned to $\mathrm{Ag}^{\mathrm{O}}$ and $\mathrm{Ag}^{+}$, respectively. The relative intensity of the peak of $\mathrm{Ag}^{+}$and the extent of silver oxidation is greater for the $\operatorname{AgRHO}(4)$ than for the $\operatorname{AgCHA}(2)$. It is interesting to note that the peak of $\mathrm{Ag}^{0}$ of the AgCHA(2)-R-Ox sample becomes narrower than that of the reduced sample, suggesting smaller NPs. 


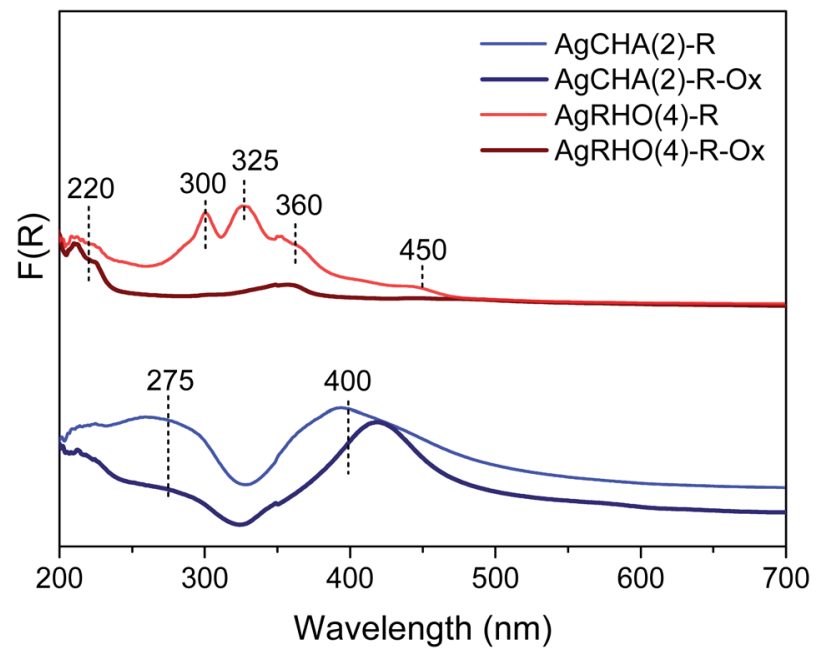

Fig. 8 UV-Vis spectra of $\mathrm{AgCHA}(2)$ and $\mathrm{AgRHO}(4)$ zeolites treated under hydrogen at $400{ }^{\circ} \mathrm{C}$ and then under $\mathrm{O}_{2}$ at $400{ }^{\circ} \mathrm{C}$.

Fig. 8 compares the UV-Vis spectra of the $\operatorname{AgCHA}(2)$ and AgRHO(4) zeolites reduced and oxidized at $400{ }^{\circ} \mathrm{C}$. The spectrum of the $\operatorname{AgCHA}(2)-\mathrm{R}$ sample after oxidation shows an intensity decrease in the region around $275 \mathrm{~nm}$, which suggest that silver clusters are oxidized to $\mathrm{Ag}^{+}$, being supported by the appareance of a new band at $220 \mathrm{~nm} \cdot{ }^{40}$ Meanwhile, the UV-Vis spectrum of the AgRHO(4)-R zeolite suffers important changes after oxidation. The disappareance of the bands at 300 and 325 $\mathrm{nm}$ indicates that $\mathrm{Ag}$ clusters evolve mostly to $\mathrm{Ag}^{+}$, as suggested by the evolution of the band at $220 \mathrm{~nm}$. Meanwhile, the weak signal at $360 \mathrm{~nm}$, attributed to $\mathrm{Ag}_{n}{ }^{0}$ clusters or small NPs, ${ }^{40}$ remains. Therefore, the whole set of physicochemical characterization spectroscopies clearly indicates that the oxidation of the reduced Ag-zeolites causes the dispersion of silver NPs and the formation of cationic $\mathrm{Ag}^{+}$, to a higher extent on the AgRHO zeolite because it contains silver clusters. This is further supported by studying AgCHA samples pre-reduced at $100{ }^{\circ} \mathrm{C}$ and $200{ }^{\circ} \mathrm{C}$ that contain mostly silver clusters. These samples upon oxidation yield mostly cationic $\mathrm{Ag}^{+}$(see Fig. S18-S19†).
Table 3 The concentration of $\mathrm{Ag}^{+}$and $\mathrm{Ag}^{0}$ species in $\mathrm{Ag}$-loaded zeolites determined from FT-IR quantitative experiments of $\mathrm{CO}$ sorption at RT and the total concentration of Ag derived from chemical analysis

\begin{tabular}{|c|c|c|c|c|}
\hline Sample & $\begin{array}{l}\mathrm{Ag} / \text { u.c. } \\
\mathrm{EDX}\end{array}$ & $\begin{array}{l}\mathrm{Ag}^{+} \\
\text {(FT-IR) }\end{array}$ & $\begin{array}{l}\mathrm{Ag}^{0} \\
\text { (FT-IR) }\end{array}$ & $\begin{array}{l}\mathrm{Ag}^{+}+\mathrm{Ag}^{0} \\
(\mathrm{FT} \text {-IR })\end{array}$ \\
\hline $\operatorname{AgCHA}(2)_{\mathrm{R} 20}{ }^{a}$ & 7.4 & 3.9 & 0.2 & 4.1 \\
\hline $\mathrm{AgCHA}(4)_{\mathrm{R} 2 \mathrm{O}}{ }^{a}$ & 3.7 & 3.6 & 0.1 & 3.7 \\
\hline $\operatorname{AgRHO}(4)_{\mathrm{R} 2 \mathrm{O}}{ }^{a}$ & 6.0 & 5.9 & 0.0 & 5.9 \\
\hline
\end{tabular}

${ }^{a}$ The nomenclature $\mathrm{R} 2 \mathrm{O}$ after the Ag-zeolite name stands for reduced at $200{ }^{\circ} \mathrm{C}$ and subsequently oxidized under $\mathrm{O}_{2}$.

The whole evolution of $\mathrm{Ag}^{+}$has been completed by studying the oxidation at $200{ }^{\circ} \mathrm{C}$ of the Ag-zeolites pre-reduced at this same temperature according to the experiment depicted in Fig. 5 for the $\operatorname{AgRHO}(2)$ zeolite (Fig. S16† for the AgCHA samples). The FT-IR spectra recorded under operando conditions during oxidation are presented in Fig. 9a for the $\mathrm{AgRHO}(4)$ zeolite (and in Fig. S20 $\dagger$ for the AgCHA samples). The $\mathrm{Ag}^{+}$ formed upon oxidation compensates for the negative framework charges, thus decreasing the number of $\mathrm{Si}(\mathrm{OD}) \mathrm{Al}$ groups, which can be monitored by the intensity decrease of the corresponding FT-IR bands. The results, plotted in Fig. 9b, show that the oxidation of silver to $\mathrm{Ag}^{+}$at $200{ }^{\circ} \mathrm{C}$ is almost complete after $3 \mathrm{~min}$ in the two AgCHA samples, whereas it reaches completion after $20 \mathrm{~min}$ for the $\mathrm{AgRHO}(2)$ zeolite (only about $20 \%$ is oxidized in $5 \mathrm{~min}$ ).

The relative stability of the silver clusters at a higher temperature was studied by oxidizing at $400{ }^{\circ} \mathrm{C}$ for $20 \mathrm{~min}$ the samples pre-reduced with $\mathrm{D}_{2}$ at $200{ }^{\circ} \mathrm{C}$. The quantitative analysis of $\mathrm{Ag}^{+}$and $\mathrm{Ag}^{0}$ species was carried out by means of infrared spectroscopy using $\mathrm{CO}$ as a probe molecule and the absorption coefficients of the $\mathrm{Ag}^{+}(\mathrm{CO})$ and $\mathrm{Ag}^{0}(\mathrm{CO})$ bands. The results,

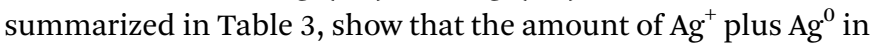
$\operatorname{AgCHA}(2)$ (reduced at $200{ }^{\circ} \mathrm{C}$ and oxidized at $400{ }^{\circ} \mathrm{C}$ ) is considerably lower than the metal loading, indicating that silver
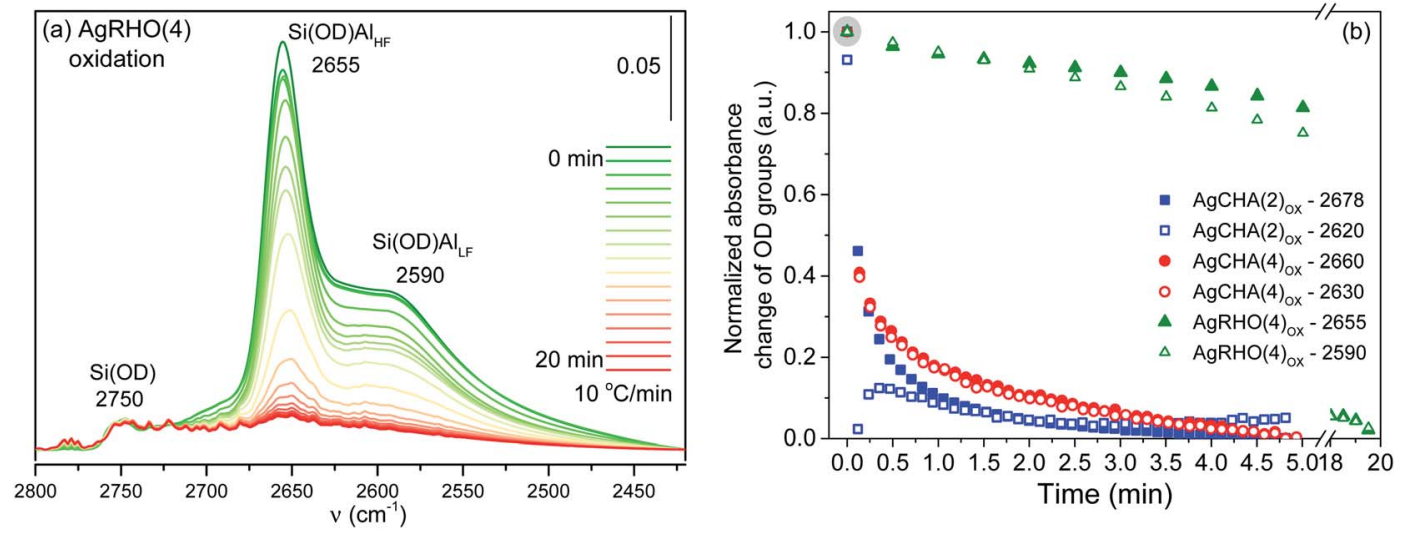

Fig. 9 (a) Time-resolved rapid scan FT-IR spectra in the region of O-D stretching vibrations of the AgRHO zeolite in contact with $\mathrm{O}_{2}$ for 20 min during heating up to $400^{\circ} \mathrm{C}$. (b) Normalized trace of the absorbance change of high-and low-frequency OD group bands during oxidation with $\mathrm{O}_{2}$ at $200^{\circ} \mathrm{C}$. 


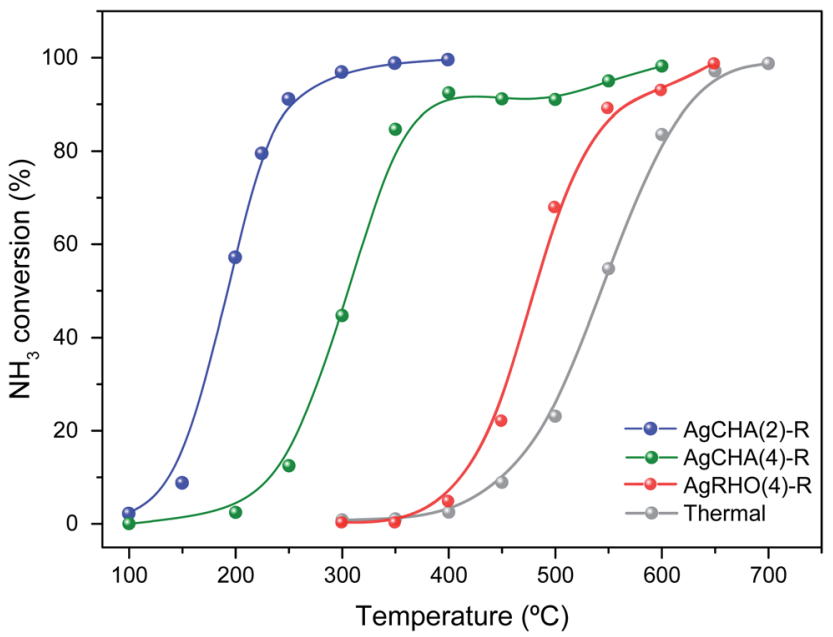

Fig. 10 Catalytic activity in the $\mathrm{NH}_{3}-\mathrm{SCO}$ reaction of $\mathrm{AgCHA}(2)$, $\mathrm{AgCHA}(4)$ and $\mathrm{AgRHO}(4)$ reduced at $400{ }^{\circ} \mathrm{C}$.

clusters and/or NPs persist after oxidation. Meanwhile, practically all silver is in the form of $\mathrm{Ag}^{+}$in the $\operatorname{AgCHA}(4)$ and AgRHO(4) samples with lower metal loadings (Table 3). Therefore, silver is completely oxidized in Ag-zeolites with lower Ag content at $400{ }^{\circ} \mathrm{C}$, in good agreement with the UV-Vis results.

\subsection{Ag-zeolites as catalysts for the $\mathrm{NH}_{3}$-SCO reaction}

Fig. 10 shows the light-off curves for the $\mathrm{NH}_{3}$ conversion during the $\mathrm{NH}_{3}-\mathrm{SCO}$ reaction on the $\operatorname{AgCHA}(2)-\mathrm{R}, \operatorname{AgCHA}(4)-\mathrm{R}$ and $\mathrm{AgRHO}(4)-\mathrm{R}$ zeolites, as well as the blank reaction run without any catalyst. There, it can be seen that the most active catalyst is $\operatorname{AgCHA}(2)-\mathrm{R}\left(T_{50 \%}=200{ }^{\circ} \mathrm{C}\right)$ followed by $\operatorname{AgCHA}(4)-\mathrm{R}\left(T_{50 \%} \approx\right.$ $275^{\circ} \mathrm{C}$ ) and the less active $\operatorname{AgRHO}(4)-\mathrm{R}\left(T_{50 \%}=475^{\circ} \mathrm{C}\right)$, while the $T_{50 \%}$ for the thermal test is $550{ }^{\circ} \mathrm{C}$. Thus, for the same zeolite structure (CHA type), in which the metal forms NPs, the activity increases with the silver loading. However, the $\operatorname{AgRHO}(4)-\mathrm{R}$ zeolite is less active than $\operatorname{AgCHA}(4)-\mathrm{R}$ despite the fact that they have similar chemical composition. This can be associated with the presence of silver clusters (i.e. absence of Ag NPs) in the AgRHO catalyst or with the blockage of the porosity by Ag species placed at the external surface of the RHO zeolite. We have excluded the latter possibility based on (i) the $\mathrm{CO}_{2}$ adsorption at $0{ }^{\circ} \mathrm{C}$ (see Fig. S21 $\dagger$ ) following the IUPAC recommendation for ultra-microporous solids ${ }^{42}$ that unambiguously confirms the microporous nature of the AgRHO adsorbing $4.5 \mathrm{mmol} \mathrm{CO}_{2}$ per $\mathrm{g}$ (see Fig. $\mathrm{S} 21 \dagger$ ) and (ii) the ammonia adsorption followed by a thermo-programmed desorption experiment coupled with mass spectrometry (TPD-MS) and adsorption and stepwise desorption of ammonia followed by IR spectroscopy (see Fig. S22 and S23† and the accompanying discussion in the ESI $\dagger$ ). Thus, it may be concluded that $\mathrm{Ag}$ clusters are nearly inactive for the selective oxidation of ammonia.

The $\mathrm{NH}_{3}$ conversion in the $\mathrm{NH}_{3}$-SCO reaction at $400{ }^{\circ} \mathrm{C}$ of the $\mathrm{AgCHA}(2)-\mathrm{R}$ is $100 \%$ and the sample keeps its brown coloration after the test. Meanwhile, the conversion is practically null for the $\operatorname{AgRHO}(4)$ zeolite at this temperature and its color turns white after the reaction. To gain further insight into the silver species, UV-Vis spectra of the post-mortem $\operatorname{AgCHA}(2)$ and $\operatorname{AgRHO}(4)$ zeolites were measured after the catalytic test at $400{ }^{\circ} \mathrm{C}$ and are compared with those of the samples reduced at $400{ }^{\circ} \mathrm{C}$ in Fig. 11. The spectrum of the $\operatorname{AgCHA}(2)-\mathrm{R}$ sample after reaction shows a decrease in the intensity of the band at $\approx 275 \mathrm{~nm}$, assigned to silver clusters and the growth of the intensity of the band at $220 \mathrm{~nm}$ attributed to $\mathrm{Ag}^{+}$, while the band at $420 \mathrm{~nm}$ of NPs remains. The UV-Vis spectrum of the postmortem AgRHO(4)-R zeolite also changes, being mainly formed by the signals at $220 \mathrm{~nm}$ and $355 \mathrm{~nm}$ assigned to $\mathrm{Ag}^{+}$ and to $\mathrm{Ag}_{n}{ }^{0}$ clusters, respectively. These results are supported by an in situ EXAFS. The $|\mathrm{FT}|$ spectra of the zeolites treated under reaction conditions at $550{ }^{\circ} \mathrm{C}$ and measured at room temperature indicate that while the NPs still exist in the used $\operatorname{AgCHA}(2)$ $\mathrm{R}$ sample, total oxidation to $\mathrm{Ag}^{+}$occurs in the $\mathrm{AgRHO}(4)-\mathrm{R}$ catalyst (see Fig. S24†). Finally, XRD data of the post-mortem catalysts further support the UV-Vis and XAS results. Indeed, $\mathrm{Ag}^{\mathrm{O}}$ peaks are clearly visible in the patterns of the reduced samples (see Fig. S25 $\dagger$ ). After $\mathrm{NH}_{3}$-SCO reaction, the metallic Ag XRD reflections disappear or strongly diminish, while the characteristic peaks of the zeolite at low angle decrease their intensities. These findings suggest that $\mathrm{Ag}^{0}$ species are oxidized to $\mathrm{Ag}^{+}$during the $\mathrm{NH}_{3}-\mathrm{SCO}$ reaction and these cationic $\mathrm{Ag}^{+}$ species compensate for the negative charge of the zeolite framework in the recovered catalysts after the reaction.

Therefore, silver NPs are much more active for the $\mathrm{NH}_{3}-\mathrm{SCO}$ reaction than silver clusters, which are practically non-active below $400{ }^{\circ} \mathrm{C}$.

\subsection{General remarks}

The results presented here give an overview on the silver species formed in the AgCHA and AgRHO zeolites submitted to different treatments. In the as-prepared materials, the $\mathrm{Ag}^{+}$and alkaline

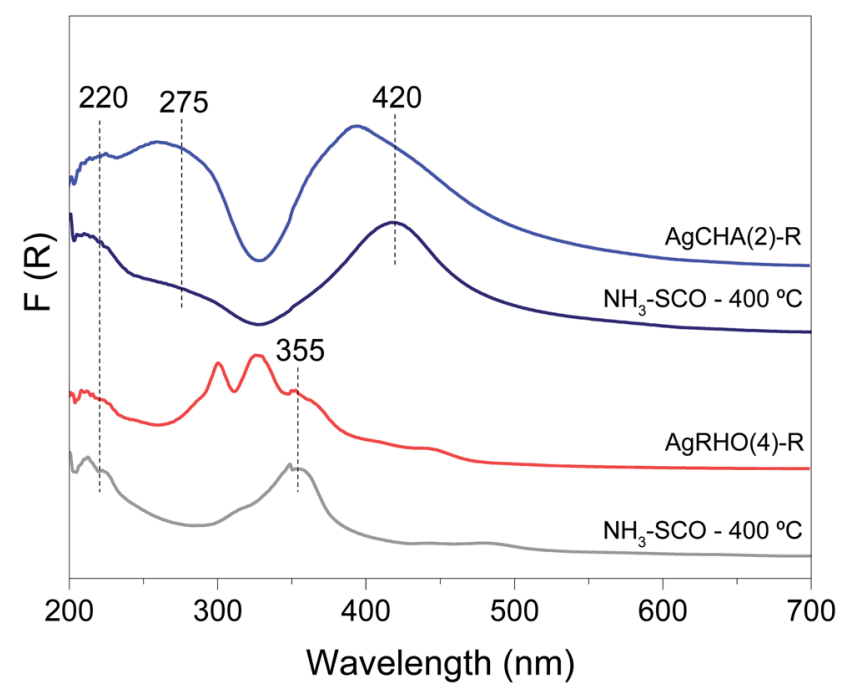

Fig. 11 UV-Vis spectra of (top) the $\mathrm{AgCHA}(2)$ zeolite reduced at $400{ }^{\circ} \mathrm{C}$ and after the $\mathrm{NH}_{3}-\mathrm{SCO}$ reaction at $400{ }^{\circ} \mathrm{C}$, and (bottom) the $\mathrm{AgRHO}(4)$ zeolite reduced at $400^{\circ} \mathrm{C}$ and after the $\mathrm{NH}_{3}-\mathrm{SCO}$ reaction at $400{ }^{\circ} \mathrm{C}$. 
cations are placed at exchange positions compensating for the negative charges associated with the presence of framework aluminum. Heating the Ag-zeolites under hydrogen provokes the reduction of $\mathrm{Ag}^{+}$to form silver clusters within the small cages and/ or NPs placed at the external surface of the zeolite. The reduction process is accompanied by the formation of Brønsted acid sites needed to keep the charge neutrality of the material. Meanwhile, the opposite effect occurs upon the oxidation of pre-reduced Agzeolites, i.e., the redispersion and oxidation of clusters or NPs and even formation of $\mathrm{Ag}^{+}$with the concomitant decrease in the number of Brønsted acid sites. Thus, different proportions of isolated $\mathrm{Ag}^{+}$, neutral or positively charged clusters and metal NPs are present in the Ag-zeolites depending on the specific reductionoxidation treatment and most remarkably on the framework topology.

The results presented here show that the silver species present in the small pore RHO- and CHA-type zeolites submitted to the same treatment are different, indicating that there exists a strong dependence on the structure. Silver clusters of few atoms are the main species in both AgCHA and AgRHO zeolites after reduction at low temperature (at $100{ }^{\circ} \mathrm{C}$ and 200 ${ }^{\circ} \mathrm{C}$ ). However, when the temperature is raised to $400{ }^{\circ} \mathrm{C}$ no significant changes occur in AgRHO, while silver clusters aggregate to form NPs in the AgCHA zeolite. The results obtained after subsequent treatment under $\mathrm{O}_{2}$ at $400{ }^{\circ} \mathrm{C}$ indicate that the degree of silver oxidation depends on the initial state in the pre-reduced Ag-zeolites. Thus, the aggregates of few atoms are fully oxidized to atomic $\mathrm{Ag}^{+}$, while metal NPs are more resistant against oxidation, being only partially dispersed and then oxidized to $\mathrm{Ag}^{+}$. Indeed, the results obtained by FT-IR spectroscopy under operando conditions on the reductionoxidation of Ag-zeolites at $200{ }^{\circ} \mathrm{C}$ show that silver clusters are easier to form and more resistant to oxidation in the RHO-type than in the CHA-type structure. Thus, silver clusters are stabilized in the RHO-type structure persisting after the treatment under $\mathrm{H}_{2}$ at $400{ }^{\circ} \mathrm{C}$, while they aggregate in the chabazite, proving that the zeolite topology strongly affects the nature of formed silver species.

The stabilization of sub-nanometer silver agglomerates within the zeolite cavities has important consequences on the physico-chemical properties of Ag-zeolites, but also on their catalytic application, as illustrated here for the $\mathrm{NH}_{3}$-SCO reaction. The AgCHA zeolites reduced at $400{ }^{\circ} \mathrm{C}$ are very active for the $\mathrm{NH}_{3}$-SCO reaction, as they contain metal NPs which are the most probable active sites. However, the AgRHO zeolite reduced at $400{ }^{\circ} \mathrm{C}$ in which the metal forms clusters is practically inactive for this reaction. Although it is not well established yet, this result proves that silver sub-nanometric aggregates are inactive for the $\mathrm{NH}_{3}$-SCO reaction. Moreover, silver clusters and metal NPs also display different stabilities under the reaction conditions since silver clusters are completely oxidized to $\mathrm{Ag}^{+}$at $400{ }^{\circ} \mathrm{C}$, which is also inactive for the reaction, while metal NPs persist.

These results prove that the choice of the zeolite topology is of key importance to develop Ag-zeolites optimized for a particular application in catalysis or any other field.

\section{Conclusions}

The results reported here indicate that the concentration and stability of silver species, i.e., $\mathrm{Ag}^{+}$, silver clusters and metal NPs formed in AgCHA and AgRHO zeolites, depend on the specific reduction/oxidation conditions and more importantly on the zeolite topology. Reduction at $100-200{ }^{\circ} \mathrm{C}$ gives rise to the formation of silver clusters in the two zeolites. When the temperature is raised to $400{ }^{\circ} \mathrm{C}$, NPs are developed in the CHAtype while small aggregates persist in the RHO-type zeolite, indicating that they are highly stable in this structure. Silver NPs formed in the AgCHA zeolite reduced at high temperature are active for the $\mathrm{NH}_{3}$-SCO reaction, while silver clusters present in the AgRHO zeolite even reduced at $400{ }^{\circ} \mathrm{C}$ are inactive for the reaction. These species also display different stabilities under oxidative conditions, so that metal NPs persist while silver clusters are completely oxidized to $\mathrm{Ag}^{+}$under oxidizing conditions or reaction conditions at $400{ }^{\circ} \mathrm{C}$.

\section{Conflicts of interest}

There are no conflicts to declare.

\section{Acknowledgements}

The authors acknowledge grant RTI2018-101784-B-I00 funded by MCIN/AEI/10.13039/501100011033 and by "ERDF A way of making Europe". Also, the project SEV-2016-0683 funded by MCIN/AEI/10.13039/501100011033 is acknowledged. The project Prometeo/2021/077, Conselleria de Educación, Cultura y Deporte de la Generalitat Valenciana is also acknowledged. K. G.-M. acknowledges Grant No. 2015/18/E/ST4/00191 from the National Science Centre, Poland. K. T. acknowledges the scholarship within the Bekker Programme (PPN/BEK/2018/1/ 00406) from the Polish National Agency for Academic Exchange. C. W. Lopes (Science without Frontiers - Process no. 13191/13-6) thanks Coordenação de Aperfeiçoamento de Pessoal de Nível Superior - Brasil (CAPES - Finance Code 001) for the predoctoral fellowship. J. Martínez-Ortigosa (SEV-20120267-02) acknowledges the Severo Ochoa Program for a predoctoral fellowship. We gratefully acknowledge the ALBA synchrotron for allocating beamtime (proposals 2016021665 and 2017032119), CLÆSS beamline staff, and particularly Carlo Marini for their help and technical support during our experiment.

\section{References}

1 L. Liu and A. Corma, Metal Catalysts for Heterogeneous Catalysis: From Single Atoms to Nanoclusters and Nanoparticles, Chem. Rev., 2018, 118(10), 4981-5079.

2 A. Baldansuren, R.-A. Eichel and E. Roduner, Nitrogen oxide reaction with six-atom silver clusters supported on LTA zeolite, Phys. Chem. Chem. Phys., 2009, 11(31), 6664-6675.

3 T. Otto, J. M. Ramallo-López, L. J. Giovanetti, F. G. Requejo, S. I. Zones and E. Iglesia, Synthesis of stable monodisperse 
AuPd, AuPt, and PdPt bimetallic clusters encapsulated within LTA-zeolites, J. Catal., 2016, 342, 125-137.

4 S. Goel, S. I. Zones and E. Iglesia, Encapsulation of metal clusters within MFI via interzeolite transformations and direct hydrothermal syntheses and catalytic consequences of their confinement, J. Am. Chem. Soc., 2014, 136(43), 15280-15290.

5 Z. Wu, S. Goel, M. Choi and E. Iglesia, Hydrothermal synthesis of LTA-encapsulated metal clusters and consequences for catalyst stability, reactivity, and selectivity, J. Catal., 2014, 311, 458-468.

6 L. Liu, U. Diaz, R. Arenal, G. Agostini, P. Concepcion and A. Corma, Generation of subnanometric platinum with high stability during transformation of a $2 \mathrm{D}$ zeolite into 3D, Nat. Mater., 2017, 16(1), 132-138.

7 L. Liu, M. Lopez-Haro, C. W. Lopes, C. Li, P. Concepcion, L. Simonelli, J. J. Calvino and A. Corma, Regioselective generation and reactivity control of subnanometric platinum clusters in zeolites for high-temperature catalysis, Nat. Mater., 2019, 18(8), 866-873.

8 L. Liu, R. Arenal, D. M. Meira and A. Corma, Generation of gold nanoclusters encapsulated in an MCM-22 zeolite for the aerobic oxidation of cyclohexane, Chem. Commun., 2019, 55(11), 1607-1610.

9 N. Salam, B. Banerjee, A. S. Roy, P. Mondal, S. Roy, A. Bhaumik and S. M. Islam, Silver nanoparticles embedded over mesoporous organic polymer as highly efficient and reusable nanocatalyst for the reduction of nitroarenes and aerobic oxidative esterification of alcohols, Appl. Catal., A, 2014, 477, 184-194.

10 R. A. Molla, K. Ghosh, B. Banerjee, M. A. Iqubal, S. K. Kundu, S. M. Islam and A. Bhaumik, Silver nanoparticles embedded over porous metal organic frameworks for carbon dioxide fixation via carboxylation of terminal alkynes at ambient pressure, J. Colloid Interface Sci., 2016, 477, 220-229.

11 A. Baldansuren, H. Dilger, R. d.-A. Eichel, J. A. van Bokhoven and E. Roduner, Interaction and Reaction of Ethylene and Oxygen on Six-Atom Silver Clusters Supported on LTA Zeolite, J. Phys. Chem. C, 2009, 113(45), 19623-19632.

12 E. Coutino-Gonzalez, W. Baekelant, D. Grandjean, M. B. J. Roeffaers, E. Fron, M. S. Aghakhani, N. Bovet, M. Van der Auweraer, P. Lievens, T. Vosch, B. Sels and J. Hofkens, Thermally activated LTA(Li)-Ag zeolites with water-responsive photoluminescence properties, J. Mater. Chem. C, 2015, 3(45), 11857-11867.

13 L. Liu, D. N. Zakharov, R. Arenal, P. Concepcion, E. A. Stach and A. Corma, Evolution and stabilization of subnanometric metal species in confined space by in situ TEM, Nat. Commun., 2018, 9(1), 574.

14 G. Agostini, S. Usseglio, E. Groppo, M. J. Uddin, C. Prestipino, S. Bordiga, A. Zecchina, P. L. Solari and C. Lamberti, From Isolated $\mathrm{Ag}+$ Ions to Aggregated Ag0Nanoclusters in Silver-Exchanged Engelhard Titanosilicate (ETS-10) Molecular Sieve: Reversible Behavior, Chem. Mater., 2009, 21(7), 1343-1353.
15 K. Morgan, A. Goguet and C. Hardacre, Metal Redispersion Strategies for Recycling of Supported Metal Catalysts: A Perspective, ACS Catal., 2015, 5(6), 3430-3445.

16 M. Moliner, J. E. Gabay, C. E. Kliewer, R. T. Carr, J. Guzman, G. L. Casty, P. Serna and A. Corma, Reversible Transformation of Pt Nanoparticles into Single Atoms inside High-Silica Chabazite Zeolite, J. Am. Chem. Soc., 2016, 138(48), 15743-15750.

17 T. Baba, N. Akinaka, M. Nomura and Y. Ono, Reversible redox behaviour between silver cations and silver metal particles in hydrated Ag-Y zeolites, J. Chem. Soc., Faraday Trans., 1993, 89(3), 595-599.

18 E. Coutino-Gonzalez, W. Baekelant, J. A. Steele, C. W. Kim, M. B. J. Roeffaers and J. Hofkens, Silver Clusters in Zeolites: From Self-Assembly to Ground-Breaking Luminescent Properties, Acc. Chem. Res., 2017, 50(9), 23532361.

19 K. Góra-Marek, K. A. Tarach, Z. Piwowarska, M. Łaniecki and L. Chmielarz, Ag-loaded zeolites Y and USY as catalysts for selective ammonia oxidation, Catal. Sci. Technol., 2016, 6(6), 1651-1660.

20 N. Popovych, P. Kyriienko, S. Soloviev, R. Baran, Y. Millot and S. Dzwigaj, Identification of the silver state in the framework of Ag-containing zeolite by XRD, FTIR, photoluminescence, 109Ag NMR, EPR, DR UV-vis, TEM and XPS investigations, Phys. Chem. Chem. Phys., 2016, 18(42), 29458-29465.

21 O. Y. Golubeva and N. Y. Ul'yanova, Stabilization of silver nanoparticles and clusters in porous zeolite matrices with Rho, Beta, and paulingite structures, Glass Phys. Chem., 2015, 41(5), 537-544.

22 F. Gao, Y. Liu, Z. Sani, X. Tang, H. Yi, S. Zhao, Q. Yu and Y. Zhou, Advances in selective catalytic oxidation of ammonia (NH3-SCO) to dinitrogen in excess oxygen: a review on typical catalysts, catalytic performances and reaction mechanisms, J. Environ. Chem. Eng., 2021, 9(1), 104575.

23 F. Wang, J. Ma, G. He, M. Chen, C. Zhang and H. He, Nanosize Effect of $\mathrm{Al} 2 \mathrm{O} 3$ in $\mathrm{Ag} / \mathrm{Al} 2 \mathrm{O} 3$ Catalyst for the Selective Catalytic Oxidation of Ammonia, ACS Catal., 2018, 2670-2682.

24 F. Wang, G. He, B. Zhang, M. Chen, X. Chen, C. Zhang and $\mathrm{H}$. He, Insights into the Activation Effect of $\mathrm{H} 2$ Pretreatment on $\mathrm{Ag} / \mathrm{Al} 2 \mathrm{O} 3$ Catalyst for the Selective Oxidation of Ammonia, ACS Catal., 2019, 9(2), 1437-1445.

25 Z. Wang, S. Li, C. Zhang, D. Wang and X. Li, The Opportunities and Challenges for NH3 Oxidation with 100\% Conversion and Selectivity. Catalysis Surveys from Asia, 2021.

26 T. Lan, Y. Zhao, J. Deng, J. Zhang, L. Shi and D. Zhang, Selective catalytic oxidation of NH3 over noble metal-based catalysts: state of the art and future prospects, Catal. Sci. Technol., 2020, 10(17), 5792-5810.

27 C. K. Lambert, Perspective on SCR NOx control for diesel vehicles, React. Chem. Eng., 2019, 4(6), 969-974.

28 L. Han, S. Cai, M. Gao, J.-y. Hasegawa, P. Wang, J. Zhang, L. Shi and D. Zhang, Selective Catalytic Reduction of NOx 
with NH3 by Using Novel Catalysts: State of the Art and Future Prospects, Chem. Rev., 2019, 119(19), 10916-10976.

29 L. Chmielarz and M. Jablonska, Advances in selective catalytic oxidation of ammonia to dinitrogen: a review, RSC Adv., 2015, 5(54), 43408-43431.

$30 \mathrm{~L}$. Zhang and $\mathrm{H}$. He, Mechanism of selective catalytic oxidation of ammonia to nitrogen over Ag/Al2O3, J. Catal., 2009, 268(1), 18-25.

31 L. Gang, B. G. Anderson, J. van Grondelle and R. A. van Santen, Intermediate Species and Reaction Pathways for the Oxidation of Ammonia on Powdered Catalysts, $J$. Catal., 2001, 199(1), 107-114.

32 L. Gang, B. G. Anderson, J. van Grondelle and R. A. van Santen, Low temperature selective oxidation of ammonia to nitrogen on silver-based catalysts, Appl. Catal., B, 2003, 40(2), 101-110.

33 J. Martinez-Ortigosa, C. W. Lopes, G. Agostini, A. E. Palomares, T. Blasco and F. Rey, AgY zeolite as catalyst for the selective catalytic oxidation of $\mathrm{NH} 3$, Microporous Mesoporous Mater., 2021, 323, 111230.

34 G. H. Penner and W. Li, Silver-109 NMR Spectroscopy of Inorganic Solids, Inorg. Chem., 2004, 43(18), 5588-5597.

35 K. Tarach, K. Góra-Marek, M. Chrzan and S. Walas, Quantification of Silver Sites in Zeolites: Carbon Monoxide Sorption Monitored by IR Spectroscopy, J. Phys. Chem. C, 2014, 118(41), 23751-23760.

36 L. Simonelli, C. Marini, W. Olszewski, M. Ávila Pérez, N. Ramanan, G. Guilera, V. Cuartero, K. Klementiev and N. L. Saini, CLAESS: The hard X-ray absorption beamline of the ALBA CELLS synchrotron, Cogent Phys., 2016, 3(1), 1231987.

37 G. Guilera, F. Rey, J. Hernández-Fenollosa and J. J. CortésVergaz, One body, many heads; the Cerberus of catalysis. a new multipurpose in-situ cell for XAS at ALBA, J. Phys.: Conf. Ser., 2013, 430, 012057.

38 B. Ravel and M. Newville, ATHENA, ARTEMIS, HEPHAESTUS: data analysis for X-ray absorption spectroscopy using IFEFFIT, J. Synchrotron Radiat., 2005, 12(Pt 4), 537-541.

39 C. Alonso-Escobar, Estudio de materiales zeoliticos como estructuras anfitrionas de nanoparticulas: aplicaciones cataliticas y medioambientales, Universitat Politècnica de València, 2017.

40 E. Sayah, D. Brouri and P. Massiani, A comparative in situ TEM and UV-visible spectroscopic study of the thermal evolution of $\mathrm{Ag}$ species dispersed on $\mathrm{Al} 2 \mathrm{O} 3$ and $\mathrm{NaX}$ zeolite supports, Catal. Today, 2013, 218-219, 10-17.

$41 \mathrm{H}$. G. Karge and E. Geidel, Vibrational Spectroscopy, in Characterization I: -/-, ed. Karge H. G. and Weitkamp J., Springer Berlin Heidelberg, Berlin, Heidelberg, 2004, pp. 1-200.

42 M. Thommes, K. Kaneko, A. V. Neimark, J. P. Olivier, F. Rodriguez-Reinoso, J. Rouquerol and K. S. W. Sing, Physisorption of gases, with special reference to the evaluation of surface area and pore size distribution (IUPAC Technical Report), Pure Appl. Chem., 2015, 87(910), 1051-1069. 